\title{
DAMPAK PEMBANGUNAN JALAN LINGKAR AMBARAWA TERHADAP PERKEMBANGAN UKM SERABI NGAMPIN AMBARAWA
}

\author{
Witjaksono Eko Hartoto, Tri Rinawati, Rita Meiriyanti, Diana Puspitasari \\ Fakultas Ekonomi, Universitas Semarang, \\ witjaksono.fe.usm@gmail.com, \\ rinaoshin@gmail.com, \\ rita.mey15@gmail.com, \\ dianapuspitasari887@yahoo.com
}

Construction of new road network ring, was actually giving an indirect impact on the socio-economic to the surrounding population. The existence of Ambarawa Ring Road is alleged to give effect to the business group pancake merchants who are members of the UKM Mekar Sari.

The method used in this research is qualitative method with phenomenological approach. Researchers describe the research subjects are traders pancake incorporated in one business group SME Ngampin Ambarawa village called Mekar Sari totaling 40 people as actors who are the target of observation or informants in a study conducted by the researchers. In this study, the types and sources of data used are primary data and secondary data.

Negative impacts to the ring road is a decrease in turnover of each of the traders pancake that is because the users prefer to go straight through the roundabout Ambarawa while the positive impact that arises in the presence of a ring road, traders are more willing to be creative that is willing to innovate products with try flavors and display products such as jackfruit, banana and sow meses cheese. It is intended to draw back buyers. This area actually has the potential and the need to touch or redirection location lots crossed by vehicles. They just need a lot of people know that they are still there, and what they contributed still feasible to provide a sensation with their typical food when passing on the street Ambarawa.

Keywords: Ring road Ambarawa, traders Serabi Ngampin.

\section{PENDAHULUAN}

A. Latar Belakang

Sejalan dengan meningkatnya pertumbuhan ekonomi suatu daerah, akan diikuti pula dengan meningkatnya arus lalu lintas kendaraan yang melewati jaringan jalan daerah tersebut, sehingga akan menimbulkan permasalahan lalu lintas. Kondisi tersebut menuntut tersedianya fasilitas yang semakin baik, terutama menyangkut sarana dan prasarana transportasi yang baik, mendukung pertumbuhan yang terjadi.

Pembangunan jaringan jalan baru yaitu jalan lingkar ternyata justru memberikan dampak tidak langsung terhadap sosial ekonomi bagi penduduk di sekitarnya. Keberadaan Jalan Lingkar Ambarawa tersebut diduga memberikan pengaruh terhadap kelompok usaha pedagang serabi yang tergabung dalam UKM Mekar Sari.

Omset penjualan pedagang serabi ngampin pada awalnya ketika jumlah pedagang serabi ngampin masih sedikit bisa mencapai Rp 360.000,- per hari atau sama dengan tiga kilo tepung adonan bahkan ada dua pedagang yang bisa menjual sampai dengan enam kilo yang sama dengan $\mathrm{Rp}$ 720.000 ,- per hari yang terjadi pada saat hari Minggu, hari liburan dan hari besar.Jumlah pedagang serabi ngampin semula berjumlah 100 orang, namun dengan adanya pembangunan jalan lingkar, pedagang serabi kini berjumlah 70 orang dan yang masih aktif 40 orang. Para peradang serabi tersebut mengeluhkan bahwa omset penjualan mereka menurun 
hingga $40 \%$. Penghasilan per harinya hanya berkisar kurang lebih Rp 120.000,per satu kilo, hal ini karena pengemudi lebih memilih jalan lingkar yang mulus dan lebar sehingga tidak melewati lokasi jualan mereka, kedai-kedai itu begitu sepi, padahal berjualan serabi merupakan andalan mereka untuk mecukupi kebutuhan hidup.

Berdasarkan uraian di atas menggambarkan bahwa adanya pembangunan jalan lingkar Ambarawa memberikan dampak terhadap perkembangan UKM Serabi Ngampin Ambarawa. Berdasarkan kondisi tersebut maka layak diteliti dengan mengkaji dan menganalisis melalui judul penelitian "Dampak Pembangunan Jalan Lingkar Ambarawa Terhadap Perkembangan UKM Serabi Ngampin Ambarawa".

\section{B. Perumusan Masalah}

Berdasarkan pada latar belakang masalah diatas, maka rumusan masalah yang diambil meliputi "Bagaimana dampak yang terjadi terhadap perkembangan UKM serabi Ngampin Ambarawa dengan adanya pembangunan Jalan Lingkar Ambarawa?"

\section{Tujuan Penelitian}

Berdasarkan perumusan masalah tersebut maka tujuan penelitian ini adalah untuk mengetahui dampak apa saja yang terjadi terhadap perkembangan UKM serabi Ngampin Ambarawa dengan adanya pembangunan Jalan Lingkar Ambarawa.

\section{TINJAUAN PUSTAKA}

\section{A. Mitos dan Fakta}

Tradisi serabinan di desa Ngampin Ambarawa Kabupaten Semarang mempunyai fungsi sebagai sarana komunikasi sosial budaya antar warga pendukungnya serta masyarakat yang datang sebagai pengunjung. Di samping itu ada kepercayaan antara dunia nyata dengan Tuhan bagi masyarakat yang mempercayainya untuk mendapatkan berkah serta permohonan kepada Tuhan agar mendapatkan jodoh melalui ritual upacara pada malam 15 Sya'ban dalam setiap tahunnya.

\section{B. Pengertian UKM (Usaha Kecil Menengah) \\ Menurut Rudjito (2003) Usaha Kecil} dan Menengah (UKM) di Indonesia yang memiliki peranan yang penting dalam perekonomian Indonesia, baik ditinjau dari segi jumlah usaha maupun dari segi penciptaan lapangan kerja.

\section{Upaya Pengembangan UKM}

Pengembangan Usaha Mikro, Kecil dan Menengah (UMKM) pada hakekatnya merupakan tanggungjawab bersama antar pemerintahan dan masyarakat. Dengan mencermati permasalahan yang dihadapi oleh UMKM, maka kedepan perlu diupaya hal-hal sebagi berikut (1) Penciptaan Iklim Usaha yang Kondisif, (2) Bantu Permodalan Pemerintahan, (3) Perlindungan Usaha, (4) Pengembangan Kemitraan, (5) Pelatihan Pemerintah, perlu meningkatkan pelatihan bagi UMKM baik dalam aspek kewiraswastaan, manajement, administrasi dan pengetahuan serta keterampilannya teori melalui pengembangan kemitraan rintisan. (6) Membentuk lembaga khusus, (7) Memantapkan Asosiasi, (8) Mengembangkan Promosi.

\section{Pemasaran Serabi Ngampin Ambarawa}

Serabi Ngampin banyak dijual di kedai-kedai kecil berderet sepanjang jalan jalan raya Ambarawa-Semarang. Kedaikedai mungil ini berdiri di sekitar kantor kelurahan Ngampin, Kecamatan Ambarawa, Kabupaten Semarang.

Dinamakan Serabi Ngampin karena memang serabi ini dijual di daerah Ngampin Ambarawa. Serabi ini juga sering disebut dengan Serabi cocor karena penggunaan kuah santan manis. 


\section{METODOLOGI PENELITIAN}

\section{A. Lokasi Penelitian}

Lokasi penelitian adalah tempat dimana penelitian akan dilakukan, untuk memperoleh data atau informasi yang berkaitan dengan permasalahan atau fokus penelitian. Adapun lokasi penelitian ini adalah desa Ngampin Ambarawa dan sepanjang jalan lingkar Ambarawa.

\section{B. Sumber Data Penelitian}

Dalam penelitian ini, sumber data menggunakan sampel purposif (purposive sample) yang memfokuskan pada informan-informan terpilih yang kaya dengan kasus untuk studi yang bersifat mendalam (Nana Syaodih, 2007). Data yang diperlukan untuk mengetahui bagaimana dampak pembangunan jalan lingkar Ambarawa terhadap perkembangan UKM Serabi Ngampin Ambarawa adalah data yang dikumpulkan melalui wawancara, observasi maupun studi dokumentasi sumber data adalah subjek dari mana data itu diperoleh.

Berdasarkan jenis data yang diperlukan, maka dalam penelitian ini yang dijadikan partisipan oleh peneliti adalah sekelompok objek yang dijadikan sumber data adalah pedagang serabi yang tergabung dalam UKM Mekar Lestari desa Ngampin Ambarawa. Adapun data yang diperoleh adalah sebagai berikut :

Tabel 1

Data Penelitian Sentra Pedagang Serabi di Kecamatan Ambarawa

\begin{tabular}{|c|l|l|l|}
\hline Desa & \multicolumn{1}{|c|}{ Jenis Produksi } & \multicolumn{1}{|c|}{ Kelompok Usaha } & \multicolumn{1}{c|}{ Anggota } \\
\hline Ngampin & Serabi & Mekar Lestari & 40 orang \\
\hline
\end{tabular}

Sumber : wawancara dengan ketua Kelompok Usaha Mekar Lestari

\section{Peubah Yang Diamati}

Fokus penelitian ini adalah menganalisis dampak yang terjadi dengan adanya pembangunan jalan lingkar Ambarawa terhadap perkembangan UKM Mekar Lestari Desa Ngampin Ambarawa. Peubah yang dimati dalam penelitian ini adalah sebagai berikut:

1. Dampak negatif pembangunan jalan lingkar Ambarawa terhadap perkembangan UKM Mekar Lestari desa Ngampin Ambarawa.

2. Dampak positif pembangunan jalan lingkar Ambarawa terhadap perkembangan UKM Mekar Lestari desa Ngampin Ambarawa.

3. Perkembangan UKM Mekar Lestari setelah pembangunan jalan lingkar Ambarawa.

\section{Model Penelitian}

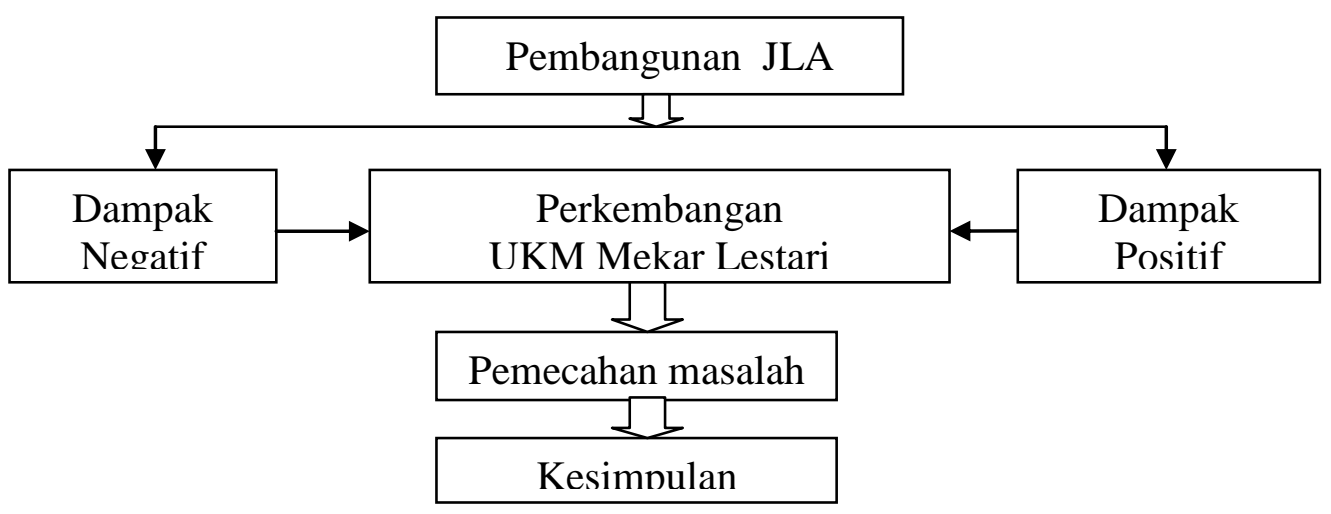




\section{E. Desain Penelitian}

Desain penelitian ini menggunakan metode kualitatif dengan pendekatan fenomenologi. Pada dasarnya penelitian ini bertujuan untuk mengetahui tentang dampak yang terjadi setelah pembangunan jalan lingkar Ambarawa serta untuk mengetahui perkembangan UKM Mekar Lestari setelah pembangunan jalan lingkar Ambarawa. Rancangan Penelitian dapat dilihat pada tabel di bawah ini:

Tabel 2

Desain Penelitian

\begin{tabular}{|l|l|}
\hline \multicolumn{1}{|c|}{ Dimension } & \multicolumn{1}{|c|}{ Fenomenologi } \\
\hline Focus & $\begin{array}{l}\text { Analisis dampak pembangunan jalan lingkar Ambarawa terhadap } \\
\text { perkembangan UKM Mekar Lestari Desa Ngampin Ambarawa }\end{array}$ \\
\hline Data Collection & Wawancara, Observasi, Dokumentasi \\
\hline Data Analysis & Deskripsi, Analisis, Interpretasi dan Penilaian \\
\hline $\begin{array}{l}\text { Product of The } \\
\text { Study }\end{array}$ & $\begin{array}{l}\text { Studi mendalam atas dampak pembangunan jalan lingkar } \\
\text { Ambarawa terhadap perkembangan UKM Mekar Lestari desa Ngampin } \\
\text { Ambarawa. }\end{array}$ \\
\hline
\end{tabular}

\section{F. Instrumen Penelitian}

Instrumen yang digunakan dalam penelitian ini disusun berupa pedoman wawancara, pedoman observasi dan pedoman dokumentasi yang dijabarkan dari kisi-kisi penelitian pada kuesioner, hal ini karena pendekatan yang digunakan dalam penelitian ini adalah pendekatan kualitatif.

Instrumen pendukung pada penelitian ini adalah alat perekam suara (MP3 player), kamera digital, serta alat tulis.

\section{G. Teknik Pengumpulan Data}

Sugiyono (2010) menyatakan pada penelitian kualitatif, pengumpulan data dilakukan pada natural setting dan teknik pengumpulan data lebih banyak pada observasi berperan serta, wawancara mendalam, dan dokumentasi.

\section{H. Teknik Analisa Data}

Sugiyono (2007) mengemukakan bahwa analisis data adalah proses mencari dan menyusun secara sistematis data yang diperoleh dari hasil wawancara, catatan lapangan dan dokumentasi, dengan cara mengorganisasikan data kedalam kategori, menjabarkan kedalam unit-unit, melakukan sintesa, menyusun kedalam pola, memilih mana yang penting dan akan dipelajari, dan membuat kesimpulan sehingga mudah dipahami oleh diri sendiri maupun orang lain.

Adapun tahapan analisis data selama proses dilakukan bersamaan dengan pengumpulan data adalah Reduksi data, Penyajian Data, Penarikan Kesimpulan.

\section{Uji Kredibitas Data}

Dalam penelitian ini menggunakan uji kredibilitas data triangulasi. Sugiyono (2011) mengemukakan bahwa triangulasi diartikan sebagai teknik pengumpulan data yang bersifat menggabungkan dari berbagai teknik pengumpulan data dan sumber data yang telah ada. Bila peneliti melakukan pengumpulan data dengan triangulasi, maka sebenarnya peneliti mengumpulkan data yang sekaligus menguji kredibilitas data, yaitu mengecek kredibilitas data dengan berbagai teknik pengumpulan data dan berbagai sumber data.

4. HASIL DAN PEMBAHASAN

A. Profil Kelompok Usaha Serabi Ngampin di Desa Ngampin 
Pedagang serabi Ngampin tergabung dalam kelompok usaha serabi dengan nama "Mekar Lestari" yang diketuai Ibu Romyati. Anggota dari kelompok usaha serabi Mekar Lestari berjumlah 40 orang tetapi yang aktif dalam setiap kegiatan dan yang masing terus berdagang bejumlah 20 orang. Kegiatan rutin dari kelompok usaha tersebut rutin dilaksanakan setiap bulan setiap tanggal enam. Kegiatan tersebut berisi tentang kegiatan arisan atau kegiatan lain yang terkait dengan usaha tersebut, misal apabila ada penyuluhan-penyuluhan dan pelatihan-pelatihan dari dinas yang terkait.

\section{B. Analisa Data}

Hasil wawancara Terstruktur dengan pedagang serabi Ngampin Ambarawa berkaitan omset penjualan dan profit

Wawancara dengan pedagang serabi Ngampin Ambarawa yang tergabung dalam kelompok usaha UKM Mekar Lestari ditujukan untuk mengetahui dampak yang timbul akibat adanya pembangunan jalan lingkar Ambarawa yaitu dengan menggali informasi ke para pedagang serabi Ngampin mengenai omzet penjualan serabi per hari. Beberapa pedagang serabi mengatakan bahwa dengan adanya jalan lingkar, omzet penjualan mereka menjadi turun karena banyak pembeli yang langsung lewat ke jalan lingkar.

Adapun hasil ringkasan wawancara dengan sepuluh pedagang serabi Ngampin yang tergabung dalam kelompok usaha "Mekar Lestari" dapat diuraikan sebagai berikut:

1. Ibu Romyati (49 tahun - ketua

kelompok usaha Mekar Lestari)

"Berdagang serabi sudah 23 tahun, omset per hari sebelum adanya jalan lingkar Ambarawa $R p$ 100.000,- yang setara dengan 1 (satu) kg tepung beras. Sedangkan omset perhari setelah adanya jalan lingkar Ambarawa Rp 80.000,- yang setara dengan $3 / 4 \mathrm{~kg}$ tepung beras. Biaya pengeluaran bahan baku per hari sebesar Rp 60.000,-. Berdagang dimulai jam 13.00
WIB sampai dengan jam 21.00 WIB. Dengan adanya JLA jelas membuat omset dan keuntungan yang didapat menjadi berkurang".

2. Ibu Kastamah (46 tahun - anggota kelompok usaha Mekar Lestari)

"Berdagang serabi sudah 9 tahun, omset per hari sebelum adanya jalan lingkar Ambarawa $R p$ 120.000,- yang setara dengan 1 (satu) $\mathrm{kg}$ tepung beras. Sedangkan omset perhari setelah adanya jalan lingkar Ambarawa Rp 90.000,- yang setara dengan $3 / 4 \mathrm{~kg}$ tepung beras. Biaya pengeluaran bahan baku per hari sebesar Rp 50.000,-. Berdagang dimulai jam 10.00 WIB sampai dengan jam 21.00 WIB. Dengan adanya JLA jelas membuat omset dan keuntungan yang didapat menjadi berkurang".

3. Ibu Sarini (49 tahun - anggota kelompok usaha Mekar Lestari)

"Berdagang serabi sudah 8 tahun, omset per hari sebelum adanya jalan lingkar Ambarawa $R p$ 120.000,- yang setara dengan 1 (satu) $\mathrm{kg}$ tepung beras. Sedangkan omset perhari setelah adanya jalan lingkar Ambarawa Rp 80.000,- yang setara dengan $3 / 4 \mathrm{~kg}$ tepung beras. Biaya pengeluaran bahan baku per hari sebesar $R p$ 50.000,-. "Berdagang dimulai jam 12.00 WIB sampai dengan jam 20.00 WIB. Dengan adanya JLA jelas membuat omset dan keuntungan yang didapat menjadi berkurang".

4. Ibu Baryati (52 tahun - anggota kelompok usaha Mekar Lestari)

"Berdagang serabi sudah 23 tahun, omset per hari sebelum adanya jalan lingkar Ambarawa Rp 100.000,- yang setara dengan 1 (satu) kg tepung beras. Sedangkan omset perhari setelah adanya jalan lingkar Ambarawa Rp 70.000,- yang setara dengan $3 / 4 \mathrm{~kg}$ tepung beras. Biaya pengeluaran bahan baku per hari sebesar Rp 60.000,-. Berdagang dimulai jam 13.00 WIB sampai dengan jam 22.00 WIB. Dengan adanya JLA jelas membuat omset 
dan keuntungan yang didapat menjadi berkurang".

5. Ibu Samilah (54 tahun - anggota kelompok usaha Mekar Lestari)

"Berdagang serabi sudah 15 tahun, omset per hari sebelum adanya jalan lingkar Ambarawa $R p$ 135.000,- yang setara dengan $1 \frac{1}{2} \mathrm{~kg}$ tepung beras. Sedangkan omset perhari setelah adanya jalan lingkar Ambarawa $R p$ 125.000,yang setara dengan $1 \mathrm{~kg}$ tepung beras. Biaya pengeluaran bahan baku per hari sebesar $R p$ 70.000,-. Berdagang dimulai jam 11.00 WIB sampai dengan jam 20.00 WIB. Dengan adanya JLA jelas membuat omset dan keuntungan yang didapat menjadi berkurang".

\section{Hasil wawancara Semi Terstruktur dengan pedagang serabi Ngampin Ambarawa berkaitan dengan inovasi produk}

1. Ibu Romyati (49 tahun - ketua

kelompok usaha Mekar Lestari)

a. "Banyak pembeli yang mencari aneka rasa seperti coklat, cocopandan, nangka, pisang tabur meses, tabur keju”.

b. "Apabila serabi dibuat dengan bentuk yang lebih menarik, pembeli akan lebih menyukai".

c. "Pembeli tidak ingin serabi dengan ukuran yang lebih besar, yang penting rasanya".

d. "Bahan baku serabi memang hanya tepung beras".

e. "Untuk meningkatkan penjualan serabi sebaiknya melakukan promosi, agar pembeli tahu bahwa antar pedagang satu dengan yang lain berbeda ketika menyajikan rasa serabi".

f. "Sebaiknya harga serabi perlu dinaikkan karena serabi sudah menggunakan varian rasa dan ukuran yang berbeda". g. "Untuk menjaga kebersihan dan hygienisnya serabi sebaiknya proses produksi perlu diperhatikan kebersihannya".

2. Ibu Kastamah (46 tahun - anggota kelompok usaha Mekar Lestari)

a. "Serabi sebaiknya dibuat bermacam-macam rasa seperti coklat, cocopandan, nangka, pisang tabur meses, tabur kejuuntuk menarik pembeli".

b. "Bentuk serabi tetap bulat karena memang cetakannya bulat dan kalau dibuat bentuk lain sepertinya tidak pas".

c. "Jika ukuran serabi lebih besar berarti harga harus dinaikkan, tetapi sepertinya sulit karena harga sudah dikenal dengan harga umumnya bahkan kadang menjual dengan harga dibawah standard".

d. "Serabi dibuat dengan bahan dasar lain belum tentu bisa karena dari bahan dasar tepung beras saja kadang agak sulit dibuat misal adonan terlalu lemes atau kaku”.

e. "Apabila menggunakan promosi internet untuk meningkatkan penjualan serabi, belum bisa menggunakannya".

f. "Menjual serabi dengan harga standard saja sulit apalagi dinaikkan karena saingannya banyak".

g. "Kebersihan adalah hal yang utama karena dengan tempat yang bersih dilihat juga bagus".

3. Ibu Sarini (49 tahun - anggota kelompok usaha Mekar Lestari)

a. "Untuk menarik minat pembeli sebaiknya melakukan inovasi 
dengan mencoba varian rasa adgar tidak bosan".

b. "Mengenai bentuk tidak bisa dirubah misak kotak atau lonjong karena cetakannya sudah bulat".

c. "Tergantung permintaan pembeli, apabila minta dengan ukuran yang lebih besar berarti harga harus dinaikkan".

d. "Serabi tidak bisa dibuat dengan bahan dasar selain tepung beras".

e. "Apabila menggunakan promosi akan menambah pembeli dari dalam maupun luar kota".

f. "Apabila akan menaikkan harga berarti serabi dibuat variasi rasa, bentuk dan kemasan".

g. "Untuk menjaga kebersihan dan hygienisnya serabi sebaiknya proses produksi perlu diperhatikan kebersihannya".

4. Ibu Baryati (52 tahun - anggota kelompok usaha Mekar Lestari)

a. "Tidak setuju serabi dirubah dengan menambah varian rasa karena akan mengubah ciri khas serabi Ngampin".

b. "Tidak setuju serabi dibuat dengan bentuk yang lebih menarik karena akan mengubah ciri khas serabi Ngampin".

c. "Tidak setuju karena bahan bakunya saja sudah mahal, apabila dibuat dengan ukuran besar maka tidak mendapatkan untung".

d. "Bahan baku serabi memang hanya tepung beras".

e. "Tidak setuju melakukan promosi karena tidak punya waktu".

f. "Tidak setuju menaikkan harga karena harga sudah disepakati oleh kelompok pedagang yaitu seribu perbuah". g. "Untuk menjaga kebersihan dan hygienisnya serabi sebaiknya proses produksi perlu diperhatikan kebersihannya".

5. Ibu Samilah (54 tahun - anggota kelompok usaha Mekar Lestari)

a. "Setuju serabi dirubah dengan menambah varian rasa seperti coklat, cocopandan, nangka, pisang tabur meses, tabur keju”.

b. "Apabila serabi dibuat bentuk yang lebih menarik itu seperti apa?".

c. "Apabila serabi dibuat ukuran yang lebih besar masaknya terlalu lama dan ukuran kemasan tidak cukup".

d. "tidak setuju membuat serabi dengan bahan dasar lainkarena rasa akan berbeda".

e. "Setuju melakukan promosi karena untuk meningkatkan penjualan".

f. "Setuju menaikkan harga tetapi pastinya modalnya yang dikeluarkan akan lebih besar".

g. "Untuk menjaga kebersihan dan hygienisnya serabi sebaiknya proses produksi perlu diperhatikan kebersihannya".

\section{Penarikan Kesimpulan}

Berdasarkan hasil wawancara terstruktur dari beberapa pedagang serabi, omset rata-rata per hari penjualan serabi sebelum pembangunan jalan lingkar Ambarawa sebesar $\mathrm{Rp}$ 177.000,- (setara 1,2 kg tepung beras) dan omset rata-rata per hari penjualan serabi setelah pembangunan jalan lingkar Ambarawa sebesar Rp 157.000,- (kurang dari $1 \mathrm{~kg}$ tepung beras). Biaya bahan baku rata-rata yang dikeluarkan sebesar $\mathrm{Rp}$ 61.000,-. Pembanguanan jalan lingkar Ambarawa menyebabkan menurunnya omset penjualan serabi, hal ini berdampak pada menurunnya keuntungan 
yang diperoleh para pedagang. Menurunnya keuntungan atau profit para pedagang serabi dapat dilihat pada tabel 4.1 terlihat profit rata-rata perhari sebelum pembangunan jalan lingkar Ambarawa sebesar Rp 116.000,sedangkan setelah pembangunan jalan lingkar Ambarawa menjadi Rp 96.000,-, jadi rata-rata profit per hari menurun sebesar $20,83 \%$.

Berdasarkan hasil wawancara semi terstruktur dari beberapa pedagang serabi menyatakan setuju apabila serabi dibuat dengan varian rasa seperti coklat, cocopandan, nangka, pisang meses, tabur keju, membuat promosi, menaikkan harga dan kebersihan (hygienies) proses produksi. Adapun untuk merubah bentuk, merubah ukuran serta merubah bahan baku dasar beberapa pedagang serabi menyatakan tidak setuju dengan berbagai variasi alasannya.

Berdasarkan keterangan di atas dapat disimpulkan bahwa beberapa pedagang serabi keberatan untuk melakukan inovasi produk karena menurut beberapa pedagang serabi tersebut, kegiatan inovasi produk akan merubah ciri khas makanan serabi yang sudah menjadi tradisi dan turun temurun. Makanan tradisional ini masih mempertahankan keklasikannya dalam proses pembuatan, yaitu dengan tungku dari tanah liat dan dibakar dengan kayu. Mungkin inilah rahasia yang tersimpan dari aroma Serabi Ngampin yang khas itu. Ada dua model Serabi yang disajikan, yaitu Serabi kering atau tanpa kuah dan Serabi basah atau Serabi dengan diberi kuah. Secara spesifik, Serabi memang tidak berasal dari Ambarawa, namun Serabi Ngampin memiliki ciri khas tersendiri. Ukuran mungil, tipis, dan punya tiga macam warna, yaitu putih, hijau dan coklat. Warna hijau dan cokelat itu sebenarnya berasal dari topping serabi. Yang coklat dari gula merah dan yang hijau dari adonan warna hijau (mungkin dari daun suji). Serabi Ngampin memiliki dua rasa, yaitu asli/original dan gula merah.

\section{KESIMPULAN}

A. Kesimpulan

Dari hasil penelitian yang diperoleh di lapangan dapat disimpulkan bahwa:

1. Dampak negatif yang timbul dengan adanya jalan lingkar bahwa omset ratarata per hari penjualan serabi menurun sebesar empat belas koma dua puluh sembilan persen. Dengan adanya dampak negatif tersebut menyebabkan keuntungan penjualan serabi dari para pedagang yang tergabung dalam UKM Mekar Lestari menurun sebesar dua puluh koma delapan puluh tiga persen.

2. Dampak positif yang timbul dengan adanya jalan lingkar adalah para pedagang lebih mau berkreasi yaitu mau melakukan inovasi produk dengan mencoba varian rasa seperti nangka, pisang meses, tabur keju. Hal ini dimaksudkan untuk menarik pembeli.

3. Solusi yang dapat diberikan akibat dari dampak pembangunan jalan lingkar adalah pemasangan papan petunjuk agar para pengguna jalan mengetahui bahwa di sepanjang jalan Ngampin Ambarawa ada makanan khas yaitu serabi yang dikenal dengan nama "Serabi Ngampin atau serabi cocor". Disamping papan petunjuk, juga diberikan pelatihan, pendampingan dan evaluasi terhadap perkembangan UKM Mekar Lestari agar terus dapat bertahan. Hal ini diharapkan dapat mempertahan tradisi dan budaya daerah serta dapat meningkatkan perekonomian daerah Ambarawa dan sekitarnya.

4. Pihak kelurahan secara optimal telah melestarikan dan menjaga warisan leluhur tersebut dengan membentuk suatu wadah dimana didalamnya terdapat koordinasi yang terorganisir untuk mengatur dan menertibkan para pedagang serabi dengan nama "UKM Mekar Lestari”. 
5. Berbagai upaya dan program pemerintah yang tercantum dalam propenas (program pokok pembangunan nasional) tahun 2015 2019, khususnya dalam pembinaan UMKM yang disinergiskan dengan potensi dan peran yang strategis, maka UKM akan menjadi kekuatan untuk menggerakkan kegiatan ekonomi masyarakat dan sekaligus dapat menjadi tumpuan dalam meningkatkan kesejahteraannya.

\section{B. Keterbatasan Penelitian}

Penelitian ini memiliki keterbatasan terutama dalam hal subjek penelitian, yaitu sebagai berikut :

1. Subjek penelitian masih terbatas pada pedagang serabi yang tergabung dalam satu kelompok usaha, sehingga diperoleh informan dan informasi yang masih terbatas.

2. Informasi yang digali hanya terbatas pada pedagang serabi sebagai pihak yang melakukan kegiatan tersebut.

\section{Agenda Penelitian Mendatang}

1. Subjek penelitian untuk penelitian mendatang diharapkan memilih sasaran yang lebih luas lagi tidak hanya mencakup pedagang serabi yang tergabung dalam kelompok usaha saja, tetapi bisa ditambahkan dengan pembeli dan pejabat yang terkait serta dinas pasar.

2. Melakukan wawancara lebih mendalam lagi kepada pedagang serabi, pembeli dan pejabat setempat yang terkait, agar mendapatkan informasi yang lebih mendalam.

3. Penelitian mendatang diharapkan dapat menggunakan wilayah penelitian di tingkat kabupaten agar dapat digeneralisasi.

\section{DAFTAR PUSTAKA}

Alexander, M. 1994. Biodegradation and Bioremediation. Academic Press, New York
Asep Hermawan, 2008. Penelitian Bisnis Paradigma Kuantitatif. Jakarta : PT Grasindo

Waluyo, Bambang, 2002, Penelitian Hukum Dalam Praktek, Jakarta: Sinar Grafika.

Effendi, Bachtiar. 2002. Pembangunan Daerah Otonomi Berkeadilan. Yogyakarta: Uhaindo dan Offset.

Eugene dan Morce (1965) dalam Tambunan, Tulus. 2001. Perekonomian Indonesia : Teori dan Temuan Empiris. Jakarta : Ghalia Indonesia

John Salindeho, 1988. Masalah Tanah dalam Pembangunan. Sinar Grafika. Jakarta

Herianto, Muhamad Roziqin, and Hardi Utomo. Dampak Pembangunan Jalan Lingkar Selatan Salatiga Terhadap Perkembangan UKM Di Sekitar Jalan Lingkar Selatan Salatiga. Jurnal Ilmiah Among Makarti 5.9 (2013).

https://portalambarawa.wordpress.com/kuli ner/serabi-ngampin/

http://manteb.com/berita/8340/Serabi.Nga mpin.Khas.Ambarawa

http://jengjeng.matriphe.com/2007/10/28/s erabi-ngampin-ambarawa-nan-segar/

Keputusan Presiden RI no. 99 tahun 1998. Pengertian Usaha Kecil.

Koentjaraningrat. 1993. Metode-metode Penelitian Masyarakat. PT. Gramedia Pustaka Utama. Jakarta.

Maria S.W. Sumardjono, 2005. Tanah: Dalam Perspektif Hak Ekonomi, Sosial Dan Budaya. cetakan kedua. Kompas Media Nusantara. Jakarta 
Mudakir Iskandar Syah, 2007. DasarDasar Pembebasan Tanah Untuk Kepentingan Umum. Cetakan 1. Jala Permata. Jakarta.

Moleong, Lexy J. (2007). Metodologi Penelitian Kualitatif. Penerbit PT Remaja Rosdakarya Offset. Bandung

Moleong L J. (2010). Metodologi Penelitian Kualitatif. Penerbit PT Remaja Rosdakarya Offset. Bandung

Moeliono, 1993. Kamus Besar bahasa Indonesia. Jakarta. Balai Pustaka.

Portes, A., Castell, M. and Benton, L.A.1989. The Informal EconomyStudies in Advanced and Less Developing Countries. Bilmore: The John Hopkins University Press.

Riyadi dan Deddy Supriyadi Bratakusumah. 2005. Perencanaan Pembangunan Daerah. Jakarta : PT Gramedia Pustaka Utama

Satori. Djam'an Dan Aan Komariah. 2010. Metode Penelitian Kualitatif. Bandung: Alfabeta, 2010

Syaodih, Nana. (2007). Metode Penelitian Pendidikan. Bandung: Rosda Karya.

Sugiyono. (2009). Metode Penelitian Bisnis (Pendekatan Kuantitatif, Kualitatif, dan $R \& D)$. Bandung: Alfabeta.
Sugiono, 2010. Metodologi Penelitian Kualitatif \& RND. Bandung. Alfabeta.

Sugiono, 2011. Metode Penelitian Pendidikan (Pendekatan Kuantitatif, Kualitatif, dan $R \& D)$; Alfabeta. Bandung.

Sugiono, 2013. Metodologi Penelitian Kualitatif \& RND. Bandung. Alfabeta.

Siagian, Sondang. P.2005. Administrasi Pembangunan, Konsep Dimensi dan Strateginya. Jakarta: Bumi Aksara.

Suryono, Agus. 2001. Teori dan Isu Pembangunan. Jakarta: UM-Press.

Satori, Djam'an. 2007. Metode Penelitian Kualitatif (Mata kuliah Analisis Penelitian Kualitatif). Bandung : Sekolah Pascasarjana Universitas Pendidikan Indonesia.

Undang-Undang No. 38/2004. tentang Penyelenggaraan Jalan

UU No. 9 tahun 1995. Kriteria usaha kecil.

UU 20/2008. Pengertian UMKM

Usman Husaini,2009. Manajemen : Teori, Praktek dan Riset Pendidikan. Jakarta: Dunia Aksara

Yuwono, Teguh. 2001. Manajemen Otonomi Daerah :Membangun Daerah Berdasarkan Paradigma Baru. Semarang: Ciyapps Diponegoro University 